\title{
New chiral stationary phase with macrocyclic glycopeptide antibiotic eremomycin chemically bonded to silica
}

\author{
S.M. Staroverov ${ }^{\text {a }}$, M.A. Kuznetsov ${ }^{\text {a }}$, P.N. Nesterenko ${ }^{\text {a,* }}$, \\ G.G. Vasiarov $^{\mathrm{b}}$, G.S. Katrukha ${ }^{\mathrm{c}}$, G.B. Fedorova ${ }^{\mathrm{c}}$ \\ ${ }^{a}$ Chemical Department, Lomonosov State University, Leninskie Gory, 119992 Moscow, Russian Federation \\ b JSC BioChemMack S\&T, Leninskie Gory, 119992 Moscow, Russian Federation \\ ${ }^{\mathrm{c}}$ Gause Institute of New Antibiotics at the Russian Academy of Medical Sciences, Bolshaya Pirogovskaya, \\ 119021 Moscow, Russian Federation
}

Received 28 September 2005; received in revised form 13 January 2006; accepted 17 January 2006

\begin{abstract}
A new chiral stationary phase (CSP) was prepared by attachment of macrocyclic glycopeptide antibiotic eremomycin to the epoxy-activated silica under mild conditions. In contrast to CSP with immobilized vancomycin, which is a close structural analogue of eremomycin, the prepared CSP reveals high enantioselectivity for separation of amino acids enantiomers. It was demonstrated by the example of ristocetin A CSP that method of the immobilization of macrocyclic glycopeptide antibiotics affects remarkably the resulting enantioselectivity.
\end{abstract}

(c) 2006 Elsevier B.V. All rights reserved.

Keywords: Eremomycin; Ristocetin A; Vancomycin; Macrocyclic glycopeptide antibiotics; Enantiomeric separations; Chiral stationary phases; Amino acids

\section{Introduction}

In recent years, the chiral stationary phases (CSPs) with covalently bonded macrocyclic glycopeptide antibiotics are found as one of the most versatile and selective chiral selectors for separation of different classes of chiral compounds [1-10]. This is mostly due to presence of various chiral recognition sites providing multiple stereoselective interactions with analytes. The enantioselectivity of silica-based CSP with attached macrocyclic glycopeptide antibiotics depends mainly on their chemical structure. So teicoplanin $[2,11]$ and ristocetin A $[3,8,11]$ containing CSPs reveals a high selectivity for separation of amino acid enantiomers, while vancomycin bonded CSP Chirobiotic V has no enantioselectivity to these substances $[1,11]$.

Another possibility to get new enantioselectivity of CSP is a chemical modification of macrocyclic glycopeptide antibiotics. Berthod et al. [5] used teicoplanin aglycone for preparation of CSP with enhanced enantioselectivity for amino acids. Ghassempour et al. [12] prepared two crystalline degradation prod-

\footnotetext{
* Corresponding author. Tel.: +7 95 9394416; fax: +7 959394675

E-mail address: PavelN@analyt.chem.msu.ru (P.N. Nesterenko).
}

ucts (CDPs) of vancomycin by alkaline hydrolysis. The attachment of CDP to aminopropylsilica resulted in CSPs having high enantioselectivity in separation of aromatic amino acids that was not noted for Chirobiotic V. The immobilization chemistry of antibiotics is also of great importance as shown by D'Acquarica [13], who synthesized and compared eleven teicoplanin containing CSPs.

The present investigation deals with preparation of new CSP with macrocyclic glycopeptide antibiotic eremomycin. The enantioselectivity of resulting CSP for separation of amino acid enantiomers was evaluated.

\section{Experimental}

\subsection{Synthesis of CSPS}

Eremomycin and ristocetin A were supplied by Institute of New Antibiotics of Russian Academy of Medical Sciences $[14,15]$. The purity of antibiotics was controlled by RP HPLC and was about $95 \%$. Vancomycin hydrochloride was purchased from Lilly Pharma Fertigung (Germany).

The initial solution was prepared by dissolving $1 \mathrm{~g}$ of eremomycin sulphate in $15 \mathrm{ml}$ of distilled water. The $\mathrm{pH}$ of solutions 
was adjusted to 8.6 with $1 \mathrm{M} \mathrm{KOH}$. The solution was mixed with $3 \mathrm{~g}$ of Diaspher-110-Epoxy $\left(5 \mu \mathrm{m}, 300 \mathrm{~m}^{2} / \mathrm{g}\right.$, pore diameter $11 \mathrm{~nm}$, carbon content $5.2 \%$ C) obtained from JSC BioChemMack S\&T (Moscow, Russia). The prepared suspension was stirred at $40^{\circ} \mathrm{C}$ within $14 \mathrm{~h}$, whereupon sorbent was filtered and washed by water, methanol and acetone and dried at $50{ }^{\circ} \mathrm{C}$ for $4 \mathrm{~h}$. The similar procedure was used for attachment of ristocetin $\mathrm{A}$ and vancomycin, when $1 \mathrm{~g}$ vancomycin or $1.2 \mathrm{~g}$ ristocetin A reacted with $5 \mathrm{~g}$ Diaspher-110-Epoxy with addition of $4 \mathrm{ml}$ ethanol to solutions of antibiotics for better solubility. The data of element analysis showed $9.5 \% \mathrm{C}, 1.5 \% \mathrm{H}, 3.3 \% \mathrm{~N} ; 13.1 \% \mathrm{C}$, $1.9 \% \mathrm{H}, 1.6 \% \mathrm{~N} ; 8.7 \% \mathrm{C}, 1.3 \% \mathrm{H}$ and $1.8 \% \mathrm{~N}$ for eremomycin, ristocetin A and vancomycin CSPs, correspondingly. It was corresponded to surface concentration $0.17-0.28 \mu \mathrm{mol}$ of bonded antibiotics per $\mathrm{m}^{2}$.

\subsection{Chromatography}

The prepared CSPs were slurry packed into $250 \mathrm{~mm} \times 4 \mathrm{~mm}$ i.d. stainless steel columns at 600 bars. The pure methanol was used as a slurry solvent and $1 \mathrm{M}$ ammonium acetate water solution was used for washing of packed column. The column efficiencies calculated from chromatographic peaks of xylene eluted in isooctane-isopropanol mixture (99:1) were 53,850 and 24,427 theoretical plates per meter for vancomycin CSP and ris-

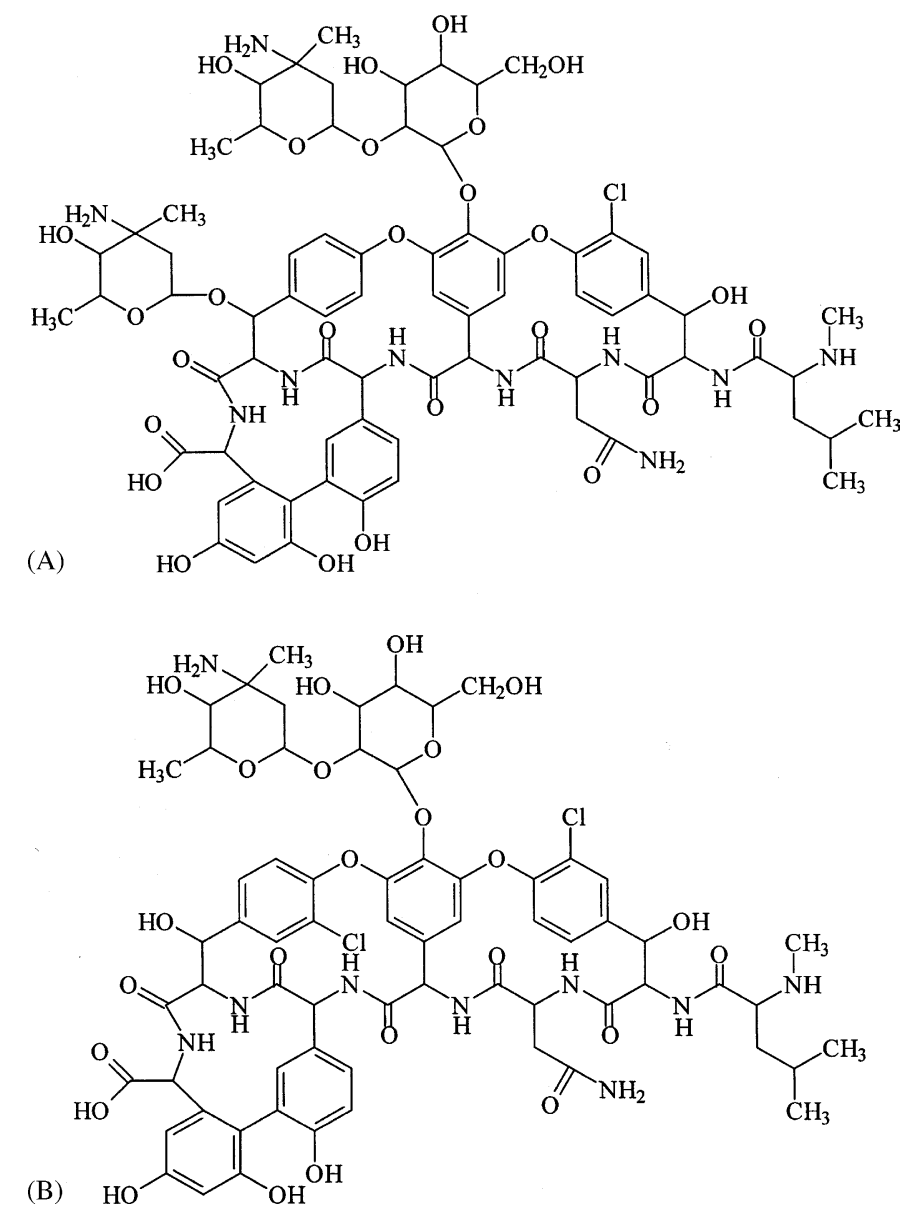

Fig. 1. Chemical structures of eremomycin (A) and vancomycin (B). tocetin A CSP columns, correspondingly. The chromatographic system consisted of K-1001 gradient pump, spectrophotometric detector K-2501, injection valve equipped with $20 \mu 1$ sample loop (all from Knauer GmbH, Berlin, Germany). All solvents were of chromatographic grade unless otherwise stated. All solutions were prepared using deionized water from Milli-Q (Millipore, Bedford, MA, USA). Amino acid standards were purchased from Sigma-Aldrich.

The chemical purity and concentration of macrocyclic glycopeptide antibiotics in reaction mixtures was controlled by RP HPLC on a $150 \mathrm{~mm} \times 4.0 \mathrm{~mm}$ i.d. Diaspher-110-C18 column (JSC BioChemMack S\&T) with mobile phase, A: 0.05\% trifluoroacetic acid; $\mathrm{B}$ : acetonitrile- $0.05 \%$ trifluoroacetic acid (42:58); linear gradient from $10 \% \mathrm{~B}$ to $60 \% \mathrm{~B}$ in $20 \mathrm{~min}$; flow rate $0.8 \mathrm{ml} / \mathrm{min}, T=25^{\circ} \mathrm{C}$, UV detection at 220 or $280 \mathrm{~nm}$. To evaluate the quality of chromatographic separations of enantiomers of amino acids, the resolution $R_{\mathrm{S}}=1.177\left(t_{\mathrm{R}, 2}-t_{\mathrm{R}, 1}\right) /\left(w_{\mathrm{b}, 1}^{0.5}+\right.$ $\left.w_{\mathrm{b}, 2}^{0.5}\right)$, and the separation factor $\alpha=k_{2} / k_{1}$ are used. The columns dead time $\left(t_{0}\right)$ was estimated by injection of solution of toluene in methanol using $100 \%$ methanol as eluent.

\section{Results and discussion}

The chemical structure of eremomycin includes 22 chiral centers, 3 cavities, 3 sugar moieties, 5 aromatic rings, 1 car-

Table 1

Chromatographic data for resolution of racemic amino acids on eremomycin CSP

\begin{tabular}{|c|c|c|c|c|}
\hline Amino acid & Mobile phase & $k_{\mathrm{L}}$ & $\alpha=k_{\mathrm{D}} / k_{\mathrm{L}}$ & $R_{\mathrm{S}}$ \\
\hline \multirow[t]{2}{*}{ DL-Alanine } & A & 0.26 & 2.37 & 2.94 \\
\hline & $\mathrm{B}$ & 0.21 & 2.86 & 4.9 \\
\hline DL- $\alpha$-Aminobutyric acid & A & 0.23 & 3.39 & 4.8 \\
\hline \multirow[t]{2}{*}{ DL-Valine } & $\mathrm{A}$ & 0.20 & 3.35 & 4.0 \\
\hline & B & 0.21 & 3.29 & $5 .($ \\
\hline \multirow{2}{*}{ DL-Norvaline } & A & 0.26 & 2.65 & 3.76 \\
\hline & B & 0.22 & 3.32 & 5.75 \\
\hline DL-Leucine & A & 0.22 & 2.54 & 3.6 \\
\hline DL-Norleucine & $\mathrm{B}$ & 0.26 & 2.00 & 3.47 \\
\hline DL-Serine & B & 0.18 & 1.50 & 1.55 \\
\hline DL-Threonine & B & 0.14 & 1.35 & 0.8 \\
\hline \multirow[t]{2}{*}{ DL-Methionine } & A & 0.26 & 2.23 & 4.19 \\
\hline & $\mathrm{B}$ & 0.28 & 2.21 & \\
\hline DL-Citrulline & $\mathrm{B}$ & 0.38 & 1.58 & 2.65 \\
\hline DL-Proline & A & 0.47 & 7.94 & 7.73 \\
\hline DL-Pipecolinic acid & A & 0.55 & 11.0 & 6.46 \\
\hline DL-Phenylglycine & A & 0.33 & 3.09 & 6.42 \\
\hline DL-Phenylalanine & $\mathrm{B}$ & 0.55 & 4.33 & 6.64 \\
\hline DL-Tyrosine & A & 0.39 & 5.05 & 9.91 \\
\hline DL-3,4-Dihydroxyphenylalanine & A & 0.72 & 4.28 & 10.03 \\
\hline DL- $m$-Fluorotyrosine & $\mathrm{B}$ & 0.84 & 3.11 & 6.87 \\
\hline \multirow[t]{2}{*}{ DL-Tryptophan } & A & 1.12 & 1.81 & \\
\hline & $\mathrm{B}$ & 2.47 & 1.73 & \\
\hline DL-(2-Thienyl)-Ala & B & 0.93 & 2.75 & 9.50 \\
\hline
\end{tabular}

Mobile phases consisted of: $\mathrm{A}=$ methanol/water $(50: 50, \mathrm{v} / \mathrm{v})$ and $\mathrm{B}=$ methanol/0.1 $\mathrm{M} \mathrm{NaH}_{2} \mathrm{PO}_{4}(20: 80, \mathrm{v} / \mathrm{v})$. 
boxylic group, 9 hydroxyl groups, 7 amido groups and 3 amino groups (Fig. 1). Eremomycin differs from vancomycin in the structure of trinucleus amino acid fragment. In this fragment, eremomycin has one chloro substituted aromatic ring, while vancomycin has two (Fig. 1). Eremomycin is a single molecule in vancomycin-related group of antibiotics having atom of chlorine in the N-terminal part of the aglycone [16]. Carbohydrate part of eremomycin molecule contains residues of glucose and eremosamine or 2,3,6-trideoxy-3-amino-3-C-methylarabinohexopiranose. The difference between eremosamine and vancosamine, which is a part of vancomycin, is in configuration of C-4 (lixohexopiranose) or 4-epi-vancosamine. Eremomycin has also two amino sugar residues [14] but not one as vancomycin.

The immobilization of eremomycin on epoxy-activated silica takes place under mild conditions from water solution and provides substantial bonding density of $50 \mu \mathrm{mol} / \mathrm{g}$ or $0.17 \mu \mathrm{mol} / \mathrm{m}^{2}$ that is comparable with $0.20 \mu \mathrm{mol} / \mathrm{m}^{2}$ published for vancomycin
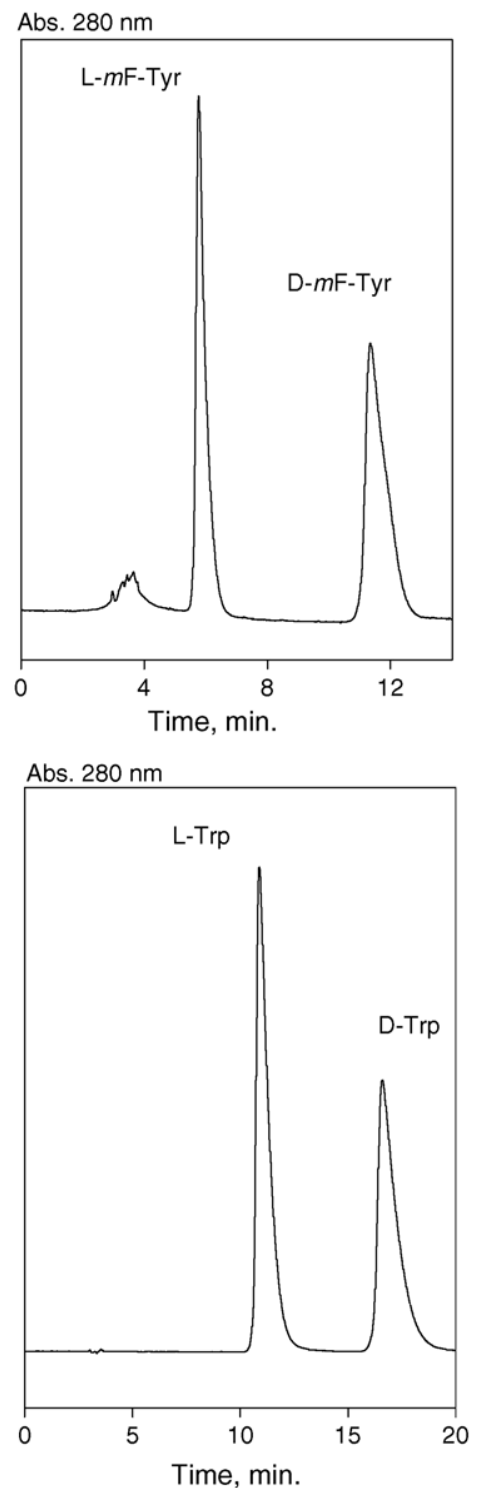

Table 2

The effect of the type of immobilization on enantioselectivity of prepared CSPS (eluent: methanol-water, 50:50, v/v)

\begin{tabular}{|c|c|c|c|c|}
\hline \multirow[t]{2}{*}{ Amino acid } & \multicolumn{2}{|c|}{ Ristocetin $\mathrm{A}^{\mathrm{a}}$} & \multicolumn{2}{|c|}{ Ristocetin $\mathrm{A}^{\mathrm{b}}$} \\
\hline & $\alpha$ & $R_{\mathrm{S}}$ & $\alpha$ & $R_{\mathrm{S}}$ \\
\hline 3,4-Dihydroxyphenylalanine & 2.50 & 5.11 & 1.33 & 1.4 \\
\hline Tyrosine & 2.66 & 4.50 & 1.30 & 1.52 \\
\hline Tryptophan & 2.03 & 4.65 & 1.23 & 1.55 \\
\hline Methionine & 2.13 & 4.22 & 1.15 & 1.52 \\
\hline$\alpha$-Aminobutyric acid & 1.30 & 1.42 & 1.26 & 1.56 \\
\hline Leucine & 5.88 & 8.30 & 1.15 & 1.45 \\
\hline Valine & 3.48 & 5.58 & 1.23 & 1.55 \\
\hline Norvaline & 3.08 & 4.80 & 1.25 & 1.58 \\
\hline Alanine & 2.56 & 3.15 & 1.14 & 1.45 \\
\hline
\end{tabular}

a CSP prepared in current investigation.

b Data from [3] for CSP with another type of immobilization chemistry.

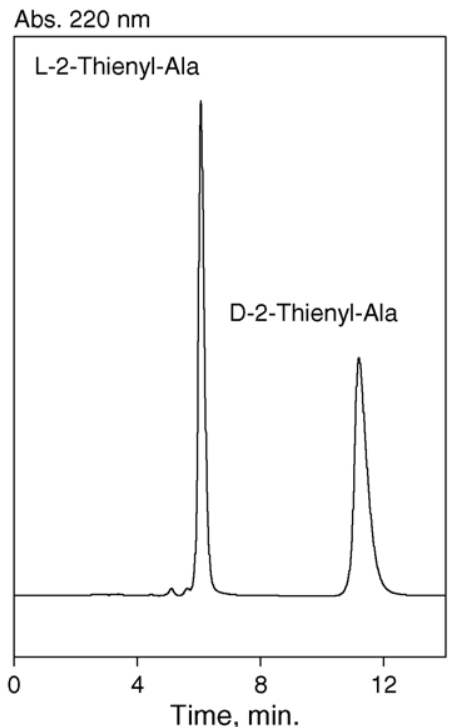

Abs. $280 \mathrm{~nm}$

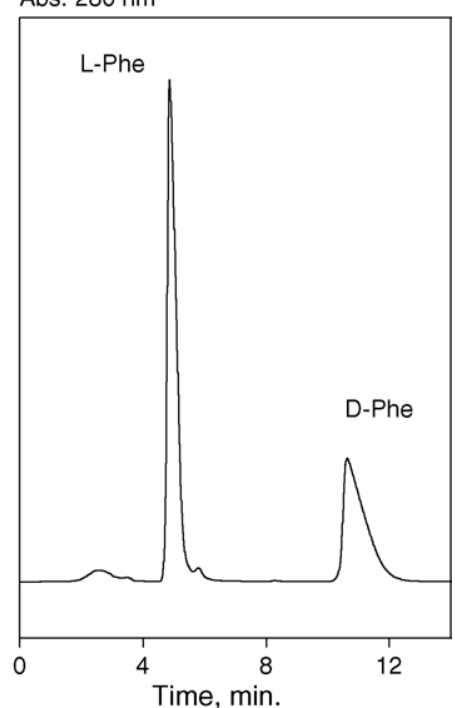

Fig. 2. Separation of enantiomers of amino acids on eremomycin CSP. Column: $250 \mathrm{~mm} \times 4.0 \mathrm{~mm}$. Eluent: methanol-0.1 $\mathrm{M} \mathrm{NaH}_{2} \mathrm{PO}_{4}(20: 80, \mathrm{v} / \mathrm{v}), 0.7 \mathrm{ml} / \mathrm{min}$. 
CSP [7] and with results obtained for alkaloids, amino acids and peptide antibiotics attached to silica [17-19]. During an attachment the concentration of antibiotics in reaction mixture was monitored by RP HPLC that allowed determination of reaction time and confirmation of absence of degradation products of antibiotic during immobilization.

The chromatographic evaluation of prepared CSP was performed in methanol-water eluents containing different buffers or additives of acetic acid. Eremomycin CSP demonstrated a high enantioselectivity in separation of amino acids, especially aromatic and cyclic iminoacids (Pro, pipecolinic acid) (Table 1). In accordance to recommendations of ASTec [11], producer of CSPs with bonded macrocyclic glycopeptide antibiotics, teicoplanin, ristocetin A and teicoplanin aglycone CSPs can be used for the separation of underivatized amino acids, but not vancomycin CSP. To exclude possible influence of bonding chemistry under comparison of different CSPs, vancomycin was attached to epoxy-activated silica under the similar procedure as for eremomycin CSP. Prepared vancomycin CSP did not show any significant retention of amino acid enantiomers in studied mobile phases $(k<0.08-0.2)$ and noticeable resolution 1.55 was achieved only for DOPA enantiomers. In fact, it confirms that the main reason for appearance of enantioselectivity in case of eremomycin CSP is different structure of bonded chiral selector: additional carbohydrate residue in eremomycin molecule, missing chlorine in aromatic ring, or combination of both factors, but not bonding chemistry.

However, the immobilization method can essentially affect the enantioselectivity of macrocyclic glycopeptide bonded phase. To check it, one more CSP containing $0.28 \mu \mathrm{mol} / \mathrm{m}^{2}$ of bonded ristocetin A was synthesized and data on enantioselectiv-

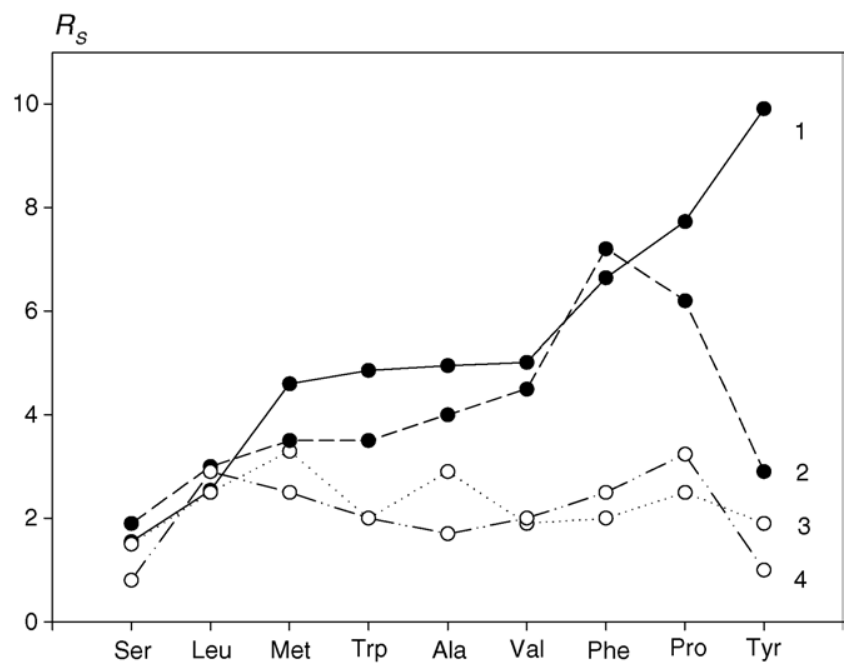

Fig. 3. Comparison of enantioresolution of amino acid enantiomers on different CSPs. 1-eremomycin CSP, 2-Chirobiotic TAG, 3-Chirobiotic R and 4-Chirobiotic T. Data accumulated from Table 1 and [11]. Mobile phases for separation of amino acids according to [11]: neutral amino acids; Chirobiotic TAG: methanol/water $(30: 70$, v/v) or methanol/water $(60: 40$, v/v); Chirobiotic R: methanol/water (50:50, v/v) or acetonitrile/water (50:50, v/v); Chirobiotic T: ethanol/water (60:40, v/v); basic amino acids; Chirobiotic TAG: methanol/100 mM NaH${ }_{2} \mathrm{PO}_{4}$ in water (50:50, v/v); Chirobiotic T: ethanol/100 $\mathrm{mM} \mathrm{NaH}_{2} \mathrm{PO}_{4}$ in water (50:50, v/v). ity for separation of amino acid enantiomers were compared with literature data for commercially available Chirobiotic R phase $[3,8,11]$. Table 2 shows the results on separation of amino acids enantiomers on two bonded phases under conditions optimal for Chirobiotic R [3]. The comparison proves that immobilization of macrocyclic glycopeptide antibiotics onto epoxy-activated silica under mild conditions can significantly improve the enantioselectivity of CSP with bonded ristocetin A in separation of amino acid enantiomers.

Thus, eremomycin CSP demonstrated good enantioresolution of amino acid enantiomers, especially for those having aromatic substitutes in their molecules. Some examples of separations of enantiomers of aromatic amino acids on eremomycin CSP are shown in Fig. 2. The enantioresolution of this chiral phase is comparable with commercially available phases with bonded macrocyclic glycopeptide antibiotics (Fig. 3).

A simplified procedure for attachment of macrocyclic glycopeptide antibiotic on epoxy-activated silica under mild conditions from water solutions is proposed. The prepared eremomycin CSP demonstrated high enantioselectivity in separation of $\alpha$-amino acid enantiomers under reversed phase mode.

\section{Acknowledgement}

This work was supported by grant N 02.467/11/3004 of Russian Federal Agency on Science and Innovations.

\section{References}

[1] D.W. Armstrong, Y. Tang, S. Chen, Y. Zhou, C. Bagwill, J.R. Chen, Anal. Chem. 66 (1994) 1473.

[2] D.W. Armstrong, Y. Liu, K.H. Ekborg, Chirality 7 (1995) 474.

[3] K.H. Ekborg-Ott, Y. Liu, D.W. Armstrong, Chirality 10 (1998) 434.

[4] K.H. Ekborg-Ott, J.P. Kullman, X. Wang, K. Gahm, L. He, D.W. Armstrong, Chirality 10 (1998) 627.

[5] A. Berthod, X.H. Chen, J.P. Kullman, D.W. Armstrong, F. Gasparrini, I. D'Acquarica, C. Villani, A. Carotti, Anal. Chem. 72 (2000) 1767.

[6] A. Berthod, T. Yu, J.P. Kullman, D.W. Armstrong, F. Gasparrini, I. D’Acquarica, D. Misti, A. Carotti, J. Chromatogr. A 897 (2000) 113.

[7] A. Berthod, U.B. Nair, C. Bagwill, D.W. Armstrong, Talanta 43 (1996) 1767.

[8] L.A. Svensson, P.K. Owens, Analyst 125 (2000) 1037.

[9] A. Cavazzini, G. Nadaini, F. Dondi, F. Gasparrini, A. Ciogli, C. Villani, J. Chromatogr. A 1031 (2004) 143.

[10] G.V. Lisichkin, A.Y. Fadeev, A.A. Serdan, P.N. Nesterenko, P.G. Mingalyov, D.B. Furman, Chemistry of surface grafted compounds, Fizmatlit, Moscow, 2003.

[11] Chirobiotic Handbook, A Guide to Using Macrocyclic Glycopeptide Bonded Phases for Chiral LC Separations, fifth ed., Advanced Separation Technologies Inc., 2004.

[12] A. Ghassempour, A. Abdollahpour, K. Tabar-Heydar, M.R. Nabid, S. Mansouri, H.Y. Aboul-Enein, Chromatographia 61 (2005) 151.

[13] I. D'Acquarica, J. Pharm. Biomed. Anal. 23 (2000) 3.

[14] G.F. Gause, M.G. Brazhnikova, N.N. Lomakina, T.F. Berdnikova, G.B. Fedorova, N.L. Tokareva, V.N. Borisova, G.Y. Batta, J. Antibiot. 42 (1989) 1790.

[15] G.F. Gause, N.N. Lomakina, A.V. Laiko, M.A. Sveshnikova, T.P. Preobrazhenskaya, G.B. Fedorova, V.N. Borisova, I.V. Tolstykh, M.S. Yurina, 
L.S. Pokras, L.E. Goldberg, I.V. Markova, E.S. Stepanova, Antibiot. Med. Biotechnol. 32 (1987) 571.

[16] N.N. Lomakina, T.F. Berdnikova, N.L. Tokareva, E.A. Abramova, N.Yu. Dokshina, Antibiot. Khimioter. 34 (1989) 254.

[17] V.A. Malinovskii, S.M. Staroverov, G.V. Lisichkin, Zh. Obschei Khimii 55 (1985) 2767.
[18] V.V. Krotov, S.M. Staroverov, P.N. Nesterenko, G.V. Lisichkin, Zh. Obschei Khimii 56 (1986) 2460.

[19] A.Y. Fadeev, P.G. Mingalyov, S.M. Staroverov, E.V. Lunina, G.V. Lisichkin, A.V. Gaida, V.A. Monastyrskii, J. Chromatogr. 596 (1992) 114. 